\title{
The Declining Middle: Occupational Change, Social Status, and the Populist Right
}

Comparative Political Studies 2020, Vol. 53(I0-II) I798-1835

(C) The Author(s) 2020

Article reuse guidelines: sagepub.com/journals-permissions DOI: $10.1177 / 00104 \mid 4020912283$ journals.sagepub.com/home/cps

\section{Thomas Kurer' ${ }^{(\mathbb{D})}$}

\begin{abstract}
This article investigates the political consequences of occupational change in times of rapid technological advancement and sheds light on the economic and cultural roots of right-wing populism. A growing body of research shows that the disadvantages of a transforming employment structure are strongly concentrated among semiskilled routine workers in the lower middle class. I argue that individual employment trajectories and relative shifts in the social hierarchy are key to better understand recent political disruptions. A perception of relative economic decline among politically powerful groups-not their impoverishment-drives support for conservative and, especially, right-wing populist parties. Individual-level panel data from three postindustrial democracies and original survey data demonstrate this relationship. A possible interpretation of the findings is that traditional welfare policy might be an ineffective remedy against the ascent of rightwing populism.
\end{abstract}

\section{Keywords}

European politics, political economy, quantitative methods

\footnotetext{
'University of Zurich, Switzerland
}

\section{Corresponding Author:}

Thomas Kurer, Department of Political Science, University of Zurich, Affolternstrasse 56, 8050 Zurich, Switzerland.

Email: kurer@ipz.uzh.ch 


\section{Introduction}

At least since the Industrial Revolution, pundits and the public alike have had a keen interest in the social and political consequences of economic modernization and the concomitant evolution of labor markets. In recent years, the most important factor behind occupational change has been technology (Goos et al., 2014; Oesch, 2013; Organisation for Economic Co-operation and Development [OECD], 2017). Rapid advances in automation and computerization push us into a new era where many existing skills and competencies become increasingly redundant. Yet, disadvantages are not distributed uniformly and contemporary innovations in technology affect distinct occupations in fundamentally different ways. Routine workers in the lower middle of the education and earnings distribution are particularly exposed to workplace automation (Autor et al., 2003). How does this politically influential group react to previously unknown level of vulnerability?

This article asks about the economic fundamentals behind recent political disruptions and examines the electoral consequences of the declining share of routine work in postindustrial labor markets. Observers have been quick to suggest that those "left behind" by economic modernization are at the root of widespread political dissatisfaction and rising anti-establishment rhetoric. But we still lack a clear picture of how a technology-induced transformation of the employment structure shapes political attitudes. While some argue that workers susceptible to automation will demand social security (Thewissen \& Rueda, 2019), others who study vote choice emphasize an anti-incumbent backlash (Frey et al., 2018) or a right-wing populist anti-establishment effect (Anelli et al., 2019; Im et al., 2019). The underlying mechanisms are not obvious, however, which is why other studies that have difficulties to reveal clear associations between material interests and political reaction conclude that noneconomic motives must prevail over economic ones (Inglehart \& Norris, 2016). As a result, contemporary research controversially discusses the cultural and economic roots of right-wing populism, Trump, Brexit, and changing patterns of mass opinion more generally (Antonucci et al., 2017; Gidron \& Hall, 2017; Mutz, 2018).

I contribute to this debate by studying routine workers' political reaction to increasingly bleak labor market prospects in the face of rapid technological progress. Routine work is prevalent in blue- and white-collar sectors and still accounts for about $25 \%-30 \%$ of the work force in advanced capitalist democracies. It has long been a highly respected kind of labor that guaranteed a decent standard of living and prospects of upward mobility (Nachtwey, 2016). But due to routine workers' distinctive susceptibility to automation, the arrival of new technology fundamentally jeopardizes this positive outlook. 
Importantly, susceptibility to automation does not necessarily imply widespread technological unemployment. Recent research has shown that the strong aggregate decline in routine work does not go hand in hand with similarly impressive replacement rates on the individual level. Technological change is a very gradual process and many routine workers manage to cling to their jobs until (early-)retirement (Cortes, 2016; Kurer \& Gallego, 2019). The aggregate decline is primarily driven by higher exit rates and lower entry rates. Superficially considered, one could thus mistake routine workers' economic situation as relatively stable. However, stability (or stagnation) in an increasingly hostile economic environment is of limited satisfaction when other parts of society are catching up or pulling away.

Routine workers' situation in an increasingly automated world of work thus provides an ideal case to disentangle the political consequences of fearing as opposed to experiencing economic adversity. In contrast to existing work that relies on snap-shot indicators of absolute economic hardship, this article brings different employment trajectories and relative shifts in economic well-being into the spotlight. While routine workers all face similar initial threats from automation, the materialized occupational trajectories are diverse and strongly differ in their material implications. I will argue that distinct employment trajectories crucially shape the relative salience of economic and noneconomic political demands. While "surviving" in an increasingly vulnerable occupational environment activates concerns about status maintenance and increases the appeal of nostalgic, socially conservative propositions, the actual experience of job loss prompts an economic response.

With that aim, I leverage individual-level panel data from Germany, Switzerland, and the United Kingdom to analyze the effect of differential employment trajectories on routine workers' political behavior. The analysis employs an empirical strategy tailored to the investigation of dynamic processes such as repeated occupational transitions, so-called marginal structural models, to estimate the effect of three distinct paths out of routine work. The results demonstrate that it is a perception of relative societal decline and concerns about one's position in the social hierarchy—not unemployment or acute material hardship — that drives support for right-wing populist parties.

The presented theoretical argument and empirical findings provide a novel reading of the economic roots of populism. I add to a burgeoning literature (e.g., Burgoon et al., 2019; Kurer \& Palier, 2019; Rodrik, 2018; Rovny \& Rovny, 2017) that relies on a relational understanding of economic disadvantage to reconcile some of the contradictions manifest in previous research. Extending the focus beyond the usual indicators of material hardship shows that fundamentally economic processes like changing labor markets might very well result in noneconomic — or not purely economic — political responses. 
On a more speculative note, the more nuanced interpretation of the structural drivers behind right-wing populist voting may also prove informative with respect to governments' leeway to respond to contemporary political disruptions. When relative societal decline rather than material hardship are at the heart of socially conservative resentment, traditional welfare policy may be an insufficient response to satisfy exposed workers and hence an ineffective remedy to counter the ascent of right-wing populist movements.

\section{Occupational Trajectories of Routine Workers}

The theoretical framework of this article follows influential work in labor economics, which builds on a simplified model economy with three task groups (Autor et al., 2003; Cortes, 2016; Spitz-Oener, 2006). As routineness is the defining feature of susceptibility to automation, we focus on the characteristics of an occupation in terms of task content rather than skill level. At the center of interest is the group of routine workers. By routine, I do not mean trivial or mundane tasks. The performed routine tasks can be relatively demanding and might require considerable training but, once the necessary rules and procedures are internalized, they are characterized by a certain repetitiveness that follows a given protocol. This repetitive trait makes such tasks "codifiable" and hence susceptible to automation (Acemoglu \& Autor, 2011). Many blue-collar jobs in factories and handicraft belong to this category but also a significant part of basic white-collar work in administration, for example, office clerks or customer service employees.

Two fundamentally different kinds of nonroutine groups exist alongside routine employment. Nonroutine cognitive (NRC) work is characterized by nonrepetitive, abstract, and cognitively demanding analytical and interactive problem-solving tasks usually requiring higher education. Think of managerial and complex professional jobs, for example, business managers, higher education teachers, or civil engineers but also workers in the creative industry. In comparison, nonroutine manual (NRM) jobs lie at the other end of the skill distribution and are characterized by relatively simple but hard-to-automate tasks, oftentimes because they require personal interaction or hand-eye coordination (Goos \& Manning, 2007). Most of these jobs are associated with lowskill service employment like taxi driving, food preparation, cleaning, or sales. ${ }^{1}$

Table 1 presents descriptive information from the three countries analyzed in the following to confirm the notion of routine workers being a sizable group in the middle of the labor force. Routine jobs $(R)$ account for about $25 \%-30 \%$ of the labor force. Male workers are slightly over-represented. Compared to $N R M$ work, routine jobs are characterized by more demanding educational requirements and, correspondingly, higher median wages. At the same time, 
Table I. Descriptive Statistics Per Country and Task Group.

\begin{tabular}{llccccc}
\hline Country & $\begin{array}{c}\text { Task } \\
\text { group }\end{array}$ & $\begin{array}{c}\text { Share of } \\
\text { labor force }\end{array}$ & $\begin{array}{c}\text { Share } \\
\text { female }\end{array}$ & $\begin{array}{c}\text { Share low- } \\
\text { skilled }\end{array}$ & $\begin{array}{c}\text { Median } \\
\text { income }\end{array}$ & $\begin{array}{c}\text { Share } \\
\text { noncitizen }\end{array}$ \\
\hline CH & NRC & 51.4 & 46.1 & 4.2 & 5525 & 7.5 \\
& R & 27.3 & 50.9 & 16.1 & 3792 & 8.1 \\
& NRM & 21.3 & 62.6 & 20.4 & 2708 & 12.1 \\
DE & NRC & 41.9 & 47.8 & 4.4 & 2505 & 5.4 \\
& R & 30.6 & 39.9 & 19.1 & 1700 & 15.8 \\
\multirow{4}{*}{ UK } & NRM & 27.5 & 49.6 & 24.5 & 1329 & 18.1 \\
& NRC & 41.1 & 47.9 & 6.4 & 1517 & 19.8 \\
& R & 23.3 & 45.1 & 21.8 & 980 & 16.8 \\
& NRM & 35.7 & 55.1 & 25.5 & 724 & 23.4 \\
\hline
\end{tabular}

NRC = nonroutine cognitive; $R=$ routine jobs; $N R M=$ nonroutine manual.

$\mathrm{CH}$ : Switzerland; DE: Germany; UK: United Kingdom.

nonroutine cognitive work is associated with even higher job quality as it clearly outperforms routine work in terms of both indicators. The final column gives an impression of the group-specific role of immigration. These numbers should only be compared within country in relative terms due to different operationalizations (shares of noncitizens in $\mathrm{CH}$ and DE; people born outside of the country in the United Kingdom) and samples that do not necessarily aim at perfectly representing the foreign-born population. Subject to these limitations, the numbers confirm that routine workers do not face the highest levels of competition from immigration, which is more prevalent in lower skilled nonroutine occupations (see Peri \& Sparber, 2009).

A major advantage of the influential task-based approach is that it provides a parsimonious framework for routine workers' universe of potential occupational transitions. While they share similar initial threats from technological innovation, they vary in their capability to escape contracting job opportunities. Three conceptually distinct task groups and the additional possibility of becoming unemployed yield the following four occupational trajectories: Upgrade ( $R \rightarrow$ NRC), survival $(R \rightarrow R)$, downgrade $(R \rightarrow N R M)$, and dropout $(\mathrm{R} \rightarrow$ unemployed).

The relatively rough classification of jobs into three task groups may be reason for concern. One might worry that the lumping of occupations blurs differences in vulnerability and thus limits the practical relevance of the described occupational trajectories. To support the underlying assumptions of differential levels of routineness and susceptibility to automation, Figure 1 provides information on the distribution of more direct, yet time-invariant, 


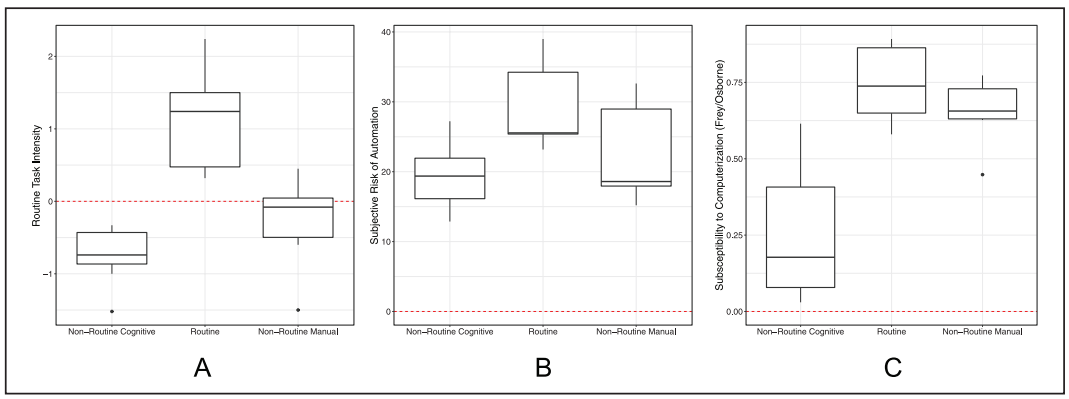

Figure I. Unweighted distributions of occupations by task group: (A) RTI, (B) subjective automation risk, and (C) Frey/Osborne.

$\mathrm{RTI}=$ routine-task intensity.

indicators of automation within and across task groups. Panel (A) shows routine-task intensity (RTI, data from Goos et al. (2014)). Panel (B) shows a measure capturing the subjective risk of replacement by robots or smart software. Data come from an original survey that will be introduced in more detail in the following. Panel (C) displays a more forward-looking indicator of susceptibility to computerization that has a stronger focus on the impact of artificial intelligence (proposed by Frey \& Osborne, 2017). All nine box plots illustrate the distribution of unweighted average values by occupation (ISCO 2-digit codes; Figure A1 in the Appendix shows occupation-specific values).

As expected, workers in routine work face the strongest automation risk. Across indicators, median values of exposure are significantly higher than those in both nonroutine groups. The result is particularly clear-cut with regard to RTI, a widely used indicator of exposure to technological innovation close to my conceptual framework. The same pattern is also reflected in subjective risk perceptions and forward-looking indicators, albeit with less pronounced differences between and larger variation within task groups. Panel (C) suggests that future technological innovation is likely to reach beyond routine work and will increasingly affect lower skilled nonroutine jobs in the service sector.

Taken together, Table 1 and Figure 1 vindicate my theoretical approach that considers routine workers a sizable at-risk group in the middle of the earnings and education distribution. While this approach provides a parsimonious framework with a feasible number of distinct occupational transitions, the presented descriptives also make clear that a classification based on a simplified model economy with three task groups certainly hides existing intra-group variation. I will take this fact into consideration in both the 
theoretical and the empirical parts of the paper. The below-reported findings should be interpreted as average effects of transitions between task groups, some of which are more consequential for respondents than others.

\section{Political Reactions to Occupational Transitions}

How do such occupational transitions affect political behavior? In recent years and decades, the radical right has increasingly challenged left parties over their traditional working-class stronghold. While routine manual workers are far from having completely abandoned the political mainstream, they endorse right-wing populist parties with a higher-than-average probability (Oesch \& Rennwald, 2018). Whether and how exactly economic factors contribute to this voter realignment remains contested. I add to this debate by studying how different employment trajectories within a vulnerable occupational environment affect vote choice. The strong risk concentration provides an opportunity to untangle whether economic threat or economic hardship better explains the appeal of right-wing populism among routine workers.

I argue that susceptibility to automation gives rise to two distinct notions of losing out. The first is concerned with economic disadvantage in a narrow sense, that is, with the straightforward consequences of unfavorable job transitions due to waning demand for routine work. The direct material implications might include negative income changes or job loss. The second notion is not necessarily tied to individual transitions but to broader changes in the social hierarchy. Jobs have meaning beyond the income they provide. As an "unintended though inevitable" consequence (Jahoda, 1982, p. 39) of its main purpose, employment is also a source of psychological well-being by offering collective purpose and social status. People strongly care about being valued by others and social status is known as a powerful motive behind individual behavior (Ridgeway, 2014).

The psychological benefit someone derives from a job strongly varies with its quality and esteem. Technological change reshapes the employment structure and hence the relative importance and value attached to different kinds of work. Once a central pillar of the lower middle class, the appreciation of routine work has strongly suffered in the age of automation as a consequence of decreasing demand and sensational media reporting on its soon extinction. A predictable industrial modernity gave way to a postindustrial risk society where traditional family arrangements, lifetime employment, and secure retirement are no longer taken for granted (Beck, 1986). While for some, the liberation of the more rigid social and economic rules might be empowering, for others, the departure from inherited traditions creates a sense of isolation, alienation, and discomfort (Ekberg, 2007). 
Consequently, routine workers who are threatened by automation have to cope with parallel challenges to both their material and psychological wellbeing. Which attitudinal reactions should we expect? Material disadvantage has long been shown to increase demand for redistribution, a strong social safety net and an encompassing, generous welfare state either as direct compensation for economic hardship or as an insurance mechanism against probable future income loss (e.g., Iversen \& Soskice, 2001; Rehm, 2009). Concerns about psychological well-being and social status, in contrast, produce reactions that transcend economic or welfare demands. A rich body of work in social psychology has implicated threat and status anxiety in the development of socially conservative or even authoritarian character traits as a general response to fear of uncertainty (e.g., Feldman \& Stenner, 1997; Jost et al., 2003; Wilson, 1973). A related literature has argued that threats to the perceived value of an ingroup negatively affect members' self-image and might create hostility toward outgroups that are seen as competitors in the social hierarchy (e.g., Riek et al., 2006). Typically, comparably higher status groups seek to derogate comparably lower status groups as a strategy of comparative status enhancement (Küpper et al., 2010).

It stands to reason that the two kinds of decline and the associated attitudinal response suggest different policy demands. Voters who experience material hardship become dependent on state support and should thus have a strong interest in a generous welfare state to cushion the economic downfall and support their re-entry in the labor market. Voters who primarily suffer from status anxiety are more likely to look for propositions that promise to maintain or reinstall their place in the social hierarchy.

The point of the matter, however, is that these distinct policy demands are hardly on the same partisan menu. While support for a strong and generous welfare state clearly suggests support for left parties, the less tangible demands related to status anxiety (conservatism, authoritarianism, status enhancement vis-a-vis outgroups) are much more likely to be satisfied by socially conservative parties on the right (Mutz, 2018) - and in particular by right-wing populist parties with an emphasis on the values and virtues of an idealized past (Andersen \& Bjørklund, 1990; Gest et al., 2017; Oesch, 2008; Steenvoorden \& Harteveld, 2018). As a consequence, there is no single party that offers credible and satisfying remedies against the parallel challenges routine workers face in times of automation. ${ }^{2}$ Instead, they have to balance and prioritize demands with respect to economic insecurity and status anxiety. I contend that occupational trajectories are key to understanding the relative salience of these two demands.

Survivors in routine work are threatened but not (yet) hit by transforming labor markets: they cling to middle-range income routine jobs and therefore 
largely safeguard the economic benefits of employment. In purely economic terms, they are clearly not the worst-off social segment in postindustrial society (see also Bornschier \& Kriesi, 2013). However, the gradual reduction in demand for routine work in times of automation goes hand in hand with dwindling societal recognition for these occupations. "Surviving" in routine work is thus first and foremost an experience of a relative decline in societal position, which highlights status anxiety, activates traditionalist predispositions, and makes socially conservative politics salient (Feldman \& Stenner, 1997). ${ }^{3}$

As a baseline expectation, I thus posit that right-wing populist parties find considerable support among survivors in routine work. What they offer is not primarily relief from economic stress but remedies against status anxiety by promoting the values of an idealized past where routine workers were a valued and crucial pillar of society. What differentiates them from left-authoritarian parties that might purport a similarly nostalgic worldview is their derogative rhetoric toward migrants as well as "undeserving" or "lazy" parts of the native population, both of which offer an obvious lower status target at which to direct hostility in an attempt of comparative status enhancement.

In the absence of a right-wing populist party, one might expect traditional conservative parties to act as a second-best option for survivors in routine work. Although not promoting the restoration of traditional order as aggressively as right-wing populists, conservative parties are credible advocates of old-established values and expected to be an attractive choice for routine workers with an interest in the status-quo ante. ${ }^{4}$

Our baseline expectation implies that a latent perception of social regression creates support for culturally conservative parties among survivors in routine work. The following analysis sets out to explore how transitions out of this environment of structural decline - for better or worse-affect routine workers' political behavior.

I stick to the different trajectories introduced above and begin with dropouts, that is, former routine workers who have been made redundant and were unable to find a new job. For dropouts, the threat of contracting employment opportunities indeed materializes. Fear turns into experience, so to speak, which drastically alters the most pressing needs. Once unemployed, actual scarcity of material resources rather than status anxiety is the most salient problem. I expect dropouts to react with an economic response, thus moving away from socially conservative parties and instead supporting the left, which traditionally and credibly promotes a generous social safety net (see also Wiertz \& Rodon, 2019).

A second likely response is political abstention. As material resources are a well-known prerequisite for political participation, now-unemployed dropouts might also increasingly stay away from the ballot box. In the light of 
adverse economic conditions resulting from the loss of labor income, individuals might prefer to spend their scarce resources on "holding body and soul together" than on "remote concerns like politics" (Rosenstone, 1982, p. 26).

Hypothesis 1a: Dropouts have a lower probability of supporting socially conservative parties than survivors.

Hypothesis 1b: Dropouts have a higher probability of supporting left parties than survivors.

Hypothesis 1c: Dropouts have a higher probability of political abstention than survivors.

The political reactions among the remaining two groups, upgraders and downgraders, are less clear-cut and the treatments arguably weaker compared to job loss. Moreover, formulating theoretical expectations for upgraders and downgraders is complicated by the so-called gradient-constraint hypothesis developed in social mobility studies. It suggests that individuals who move between occupational groups will differ in behavior from their class of origin as well as from their class of destination and instead form preferences that lie somewhere in between (Ares, 2020; Lahtinen et al., 2017). Hence, I have weaker theoretical priors with respect to routine workers who upgrade or downgrade.

Upgraders were able to escape the squeeze in the middle for the better and find safer and presumably better-paid work in nonroutine cognitive occupations. This subgroup therefore experienced the bright side of a market-based allocation of jobs and might be more likely to vote for parties promoting free markets and limited government interventions.

Hypothesis 2a: Upgraders have a lower probability of supporting socially conservative parties than survivors.

Hypothesis 2b: Upgraders have a higher probability of supporting promarket liberal parties than survivors.

Downgraders, on the other hand, experienced a certain decline in status and, most likely, material resources but they were able to remain in the labor force and uphold at least some labor income and economic independence. A priori, it is not obvious which of these counteracting processes dominate their political response. Moreover, the above discussion of the classification of occupations into broad task groups has shown that in particular between routine and NRM workers there is some overlap regarding susceptibility to automation. Hence, we have reason to expect that the individual perception of this specific 


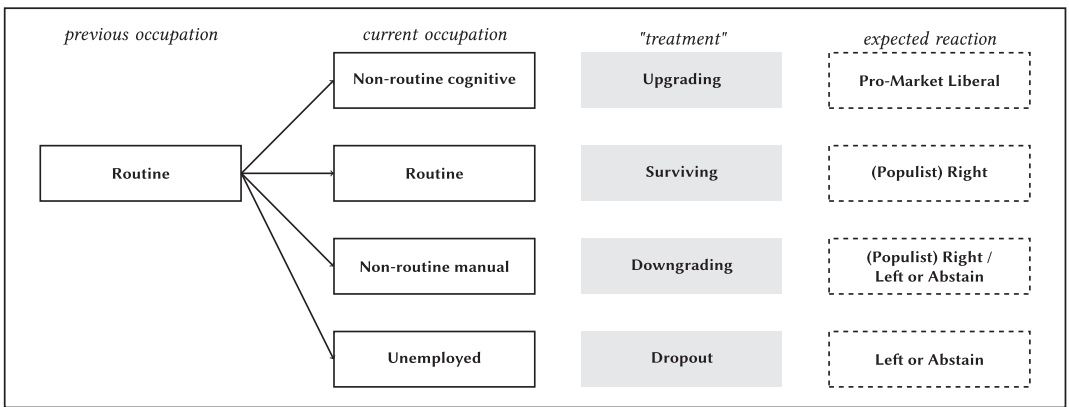

Figure 2. Theoretical framework.

transition and the resulting political reaction might be less pronounced compared to other transitions. Still, for the sake of completeness, I formulate the following testable hypotheses.

Hypothesis 3a: Downgraders have a lower probability of supporting socially conservative parties than survivors.

Hypothesis 3b: Downgraders have a higher probability of supporting left parties than survivors.

Hypothesis 3c: Downgraders have a higher probability of political abstention than survivors.

Figure 2 provides a summary of the theoretical framework and the expected political reaction to the specific occupational transitions under study.

\section{Empirical Strategy}

\section{Data and Operationalization}

Individual-level panel data with detailed information on respondents' occupation spanning over a reasonably long time period are an essential prerequisite to study the questions at hand. I collected all European household panel surveys that meet these conditions, combined all available waves, and harmonized the coding of key indicators over time and between datasets. This procedure results in a large comparative, longitudinal micro-level data set including Germany, Switzerland, and the United Kingdom and covering the time span of the late 1980s until now (see Table 2).

The three cases provide valuable variation in institutional context and party system, which allows for hypothesis testing under a variety of 
Table 2. Data Sources and Final Sample Size.

\begin{tabular}{llrr}
\hline Country & \multicolumn{1}{c}{ Data source } & Time span & Sample \\
\hline Switzerland & Swiss Household Panel (SHP) & $1999-2014$ & 8,871 \\
Germany & Socio-Economic Panel (SOEP) & $1989-2016$ & 22,699 \\
UK & British Household Panel Survey (BHPS) & $1991-2008$ & 24,487 \\
& Understanding Society (UKHLS) & $2009-2015$ & \\
\hline
\end{tabular}

circumstances and enhances credence in the external validity of the results. Switzerland provides the largest number of parties and is characterized by the presence of a strong right-wing populist party throughout the entire time period under study. Furthermore, the so-called consensus system traditionally involves all large parties, which makes preference-based vote choice plausible and reduces the probability of voting based on nonideological patterns of retrospective economic voting. The United Kingdom has long been dominated by two large parties, facilitated by its majoritarian model of democracy. However, the recent rise of UK Independence Party (UKIP) makes it possible to test the right-wing populism hypothesis in a different institutional context. We would expect lower baseline probabilities of support for nonmainstream parties due to strategic considerations in a first-past-the-post system but similar patterns of changing support as a reaction to occupational transitions. The proportional election system and diverse party supply in Germany, too, offers various political options to voters with one crucial difference during most of the time period under study: the absence of a right-wing populist party. ${ }^{5}$ Just as the United Kingdom before 2013, this constellation will allow to test whether conservative parties indeed serve as second-best option for voters in an increasingly gloomy occupational environment of routine work.

The most important variable for the present analysis is occupational task group. Following the influential Autor-Levy-Murnane model (Autor et al., 2003), each occupation is classified into one task group $j \in\{N R C, R, N R M\}$, that is, nonroutine cognitive, routine, and nonroutine manual. This classification relies on detailed occupational dictionaries that describe the main activities required to perform a job. We build on existing classifications provided by Oesch (2013) and Cortes (2016) and group occupations based on fine-grained information (ISCO four-digit) into task groups. Appendix Table A1 provides the detailed coding.

This grouping into three task groups $j \in\{N R C, R, N R M\}$ plus the additional option of unemployment $U$ yields a straightforward analytical framework to study occupational transitions. A "survivor" in routine work is a respondent with $j_{i, t}=j_{i, t-p}=R$, where $p$ denotes the most proximate previous observation. ${ }^{6}$ Surviving in routine work will serve as a reference category 
in the empirical models. Upgraders are individuals who have been classified as routine worker $R$ in $t-p$ but fall into the category of nonroutine cognitive work $N R C$ in $t$. The same logic applies to downgraders and dropouts. From these individual occupational transitions, I create the central explanatory variable, a multivalued treatment $D_{i, t}$. The strict coding ensures that we only study effects of within-individual transitions

$$
D_{i, t}= \begin{cases}0, & \text { if } j_{i, t}=R \wedge j_{i, t-p}=R \\ 1, & \text { if } j_{i, t}=N R C \wedge j_{i, t-p}=R \\ 2, & \text { if } j_{i, t}=N R M \wedge j_{i, t-p}=R \\ 3, & \text { if } j_{i, t}=U \wedge j_{i, t-p}=R\end{cases}
$$

The dependent variable, vote intention, varies between countries and is created from the specific items in the respective data source (see Appendix Table A2). It should be noted that the independent questionnaires of the three data sources result in slightly differing operationalizations of the dependent variable, in particular with respect to abstention.

Given the focus of this study, I restrict the sample to respondents who at some point in their employment history hold a routine job. The final data set consists of individuals who have been in routine work in $t-p$ and who are in one of the four previously defined occupational states $j \in\{N R C, R, N R M, U\}$ in $t$. An individual contributes multiple observations to the sample, especially if she/he remains in routine work. The sample is further restricted to individuals of age 18 years or more but younger than 65 years who are eligible to vote (i.e., have citizenship of the respective country).

\section{Estimation of Dynamic Processes}

Personal and contextual characteristics determine the likelihood and direction of a transition out of routine work. The standard approach to correct for selection is controlling for confounders. However, applied to dynamic processes like occupational trajectories, controlling itself introduces bias if confounders change over time and are potentially affected by previous treatment. For example, losing a routine job and becoming unemployed is more likely in some regions than in others. Insofar, region is a predictor of occupational transitions. However, unemployment then perhaps forces this person to move to another region of the country, which means that region is also a consequence of an occupational transition and the new place of residence is likely to influence both future occupational transitions as well as future political preferences. In essence, in a dynamic longitudinal analysis, such time-varying confounders are pretreatment and posttreatment variables at the same time (Blackwell, 2013). 
With conventional (fixed-effects) regression or matching methods, the researcher is left with an uncomfortable trade-off: either conditioning on the time-varying confounder, thus getting rid of omitted variable bias at the cost of potential posttreatment bias, or dropping the confounder, which avoids posttreatment bias but induces omitted variable bias. Marginal structural models (MSM) have been suggested as a hedge against this dilemma. Originally introduced in biostatistics (Robins, 1999; Robins et al., 2000), the value of MSMs for the frequent occurrence of dynamic treatments in social sciences has been emphasized in recent contributions (Bacak \& Kennedy, 2015; Blackwell, 2013; Blackwell \& Glynn, 2018).

Three steps are involved in the estimation of an MSM. The first step is concerned with the treatment model. How likely is an individual to receive one or the other treatment, that is, for example, to upgrade or downgrade in the occupational structure? As we are dealing with observational data, individual probabilities of treatment are unknown and have to be estimated empirically. Treatment assignment at each time point is modeled conditional on theoretically derived determinants of treatment assignment as well as on the observed past, including the treatment history of a respondent.

Second, for every respondent in the sample, I create a weighting variable for each time point $t$ that is equal to the inverse product of the calculated conditional probabilities at $t$. Re-weighting observations with the inverse individual probability of receiving treatment at $t$ creates a pseudo-population where dynamic selection is eliminated, that is, where treatment assignment is unaffected by confounding. For example, a routine worker living in a region with bad labor market performance at $t$ might have a higher probability to become unemployed, so she/he has a higher probability to receive the "treatment" dropout. Weighting these respondents by the inverse of a high probability will downweight their influence and help achieve balance in the sample, that is, reduce confounding based on place of residence.

As a last step, I run the outcome model: To estimate the causal parameter of the MSM, I perform a series of weighted linear regressions of the dependent variable, party choice (dichotomized), on the multivalued treatment variable capturing occupational transitions out of routine work. Importantly, this model avoids conditioning on time-varying covariates as confounding is accounted for via weighting instead of controlling. In contrast to standard regression or matching procedures, we never explicitly condition on confounders in the outcome model and thereby eliminate the threat of introducing posttreatment bias due to covariates that dynamically evolve over time (Blackwell, 2013).

For the specification of the treatment model (step 1), expert knowledge on the determinants of occupational transitions is key. Fortunately, a rich body 
of work in labor economics and economic sociology provides clear guidance in that regard. First of all, studies on local labor markets have emphasized a strong spatial component to occupational change, driven separately by globalization and technological progress (Autor et al., 2013). Regarding individual traits, Cortes (2016) shows that the sorting mechanism out of routine work depends on ability and skills: Especially routine workers with remarkable cognitive resources face a realistic chance of an occupational upgrade. Furthermore, women appear to be much more likely than men to leave declining routine jobs but often end up in lower paid nonroutine jobs (Murphy, 2014). Age also matters: Especially young routine workers climb the occupational ladder, while prime age and older workers remain in the contracting occupations of routine employment (Autor \& Dorn, 2009). In addition, unions are likely to play a role regarding occupational transitions and employment protection. Members of a trade union might be less vulnerable to unemployment and potentially more stably embedded in their current job, thus making transitions less likely (Parolin, 2020). Hence, the five most important determinants of the sorting mechanism appear to be region, education, gender, age, and union membership. This is the core of the treatment model. Variable selection is justified by model fit (Akaike information criterion [AIC]), which is best in the full treatment model, that is, better than in any specification omitting any of the core variables.

In addition, MSMs exploit the longitudinal data structure and take into account the entire treatment history of an individual. We rely on a combination of a one-period lagged treatment variable and the cumulative treatment history (share of years treated) of each respondent. Year dummies are included to adjust for period effects. A multinomial model then regresses the multivalued treatment $D_{i, t}$ on the covariates and treatment history to generate individual, dynamic weights for each respondent. ${ }^{7}$

MSMs properly adjust for both selection into treatment and measured confounding if the treatment model satisfies the following four assumptions: consistency, exchangeability, positivity, and no misspecification (Cole \& Hernán, 2008). We provide a more detailed discussion of the validity of these assumptions in the Supplemental Material along with an extensive sensitivity analysis of the baseline model, which demonstrates that the results do not hinge on the specific modeling choices of the main analysis.

It should be noted that a causal interpretation of the MSM results is hampered by the possibility of remaining differences between routine survivors and respondents who transition out of routine work, for example, in terms of attitudes or temperament. While the treatment history might take up part of that variation, such unmeasured and potentially time-varying factors are hard to completely account for. The robustness section will discuss demeaned 


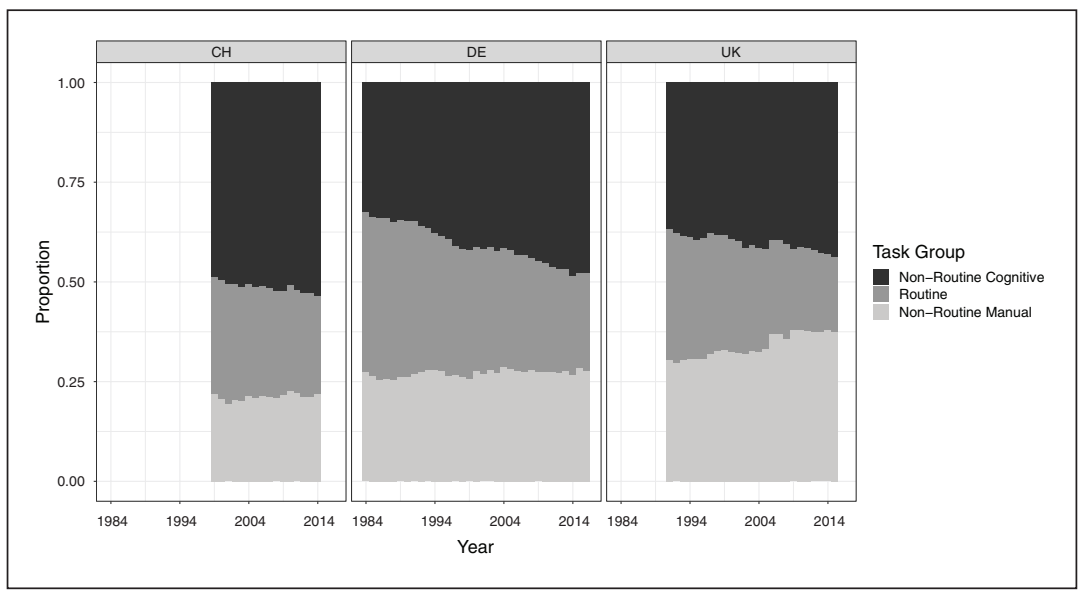

Figure 3. Relative share of task groups over time.

results that promise some improvement at least with regard to time-invariant unobservables.

\section{Results}

\section{Occupational Transition Patterns}

The first part of the empirical section exploits the richness of the comparative longitudinal data to report some descriptive evidence on country-specific patterns of occupational change and the relative frequency of routine worker's distinct employment trajectories. Figure 3 describes country-specific patterns of occupational change and reveals somewhat distinct employment structures with one striking commonality: The decline of routine jobs. Switzerland has long been characterized by a strong concentration of jobs in highly skilled and specialized nonroutine cognitive occupations, a trend that has been reinforced during the last decade. Routine jobs have been less important already at the beginning of the observed period but continued to decline over time. The longer time span available for Germany, in comparison, reveals the dominant position of routine jobs in the 1980s - as well as their remarkable demise over time. At the same time, Switzerland and Germany display a strong and persistent trend of occupational upgrading evidenced by an ever-increasing share of work in demanding analytical and/or interactive occupations. 
Table 3. Individual Occupational Transition Patterns (column percentages).

\begin{tabular}{lrcrrcccccc}
\hline & \multicolumn{3}{c}{ Switzerland } & \multicolumn{3}{c}{ Germany } & \multicolumn{3}{c}{ United Kingdom } \\
\cline { 2 - 9 } Last & \multicolumn{4}{c}{ Initial occupation } \\
\cline { 2 - 10 } occupation & NRC & R & NRM & NRC & R & NRM & NRC & R & NRM \\
\hline NRC & $88.0 \%$ & $15.5 \%$ & $17.0 \%$ & $85.6 \%$ & $17.3 \%$ & $12.9 \%$ & $85.3 \%$ & $18.0 \%$ & $14.2 \%$ \\
R & $6.5 \%$ & $73.2 \%$ & $12.1 \%$ & $8.0 \%$ & $67.8 \%$ & $12.9 \%$ & $6.9 \%$ & $65.1 \%$ & $9.3 \%$ \\
NRM & $5.5 \%$ & $11.3 \%$ & $70.9 \%$ & $6.4 \%$ & $14.9 \%$ & $74.1 \%$ & $7.9 \%$ & $16.8 \%$ & $76.5 \%$ \\
\hline
\end{tabular}

Within-individual transitions between first and last observation in panel (column percentages). $\mathrm{NRC}=$ nonroutine cognitive; $\mathrm{R}=$ routine jobs; $\mathrm{NRM}=$ nonroutine manual.

The employment structure in the United Kingdom has evolved rather differently. A similar decrease in routine work and a moderate increase in highskilled jobs are accompanied by enduring job growth at the lower end of the skill spectrum. These patterns reflect earlier findings, which concluded that Britain's hollowing of the middle goes hand in hand with a persistent growth in low-skilled service jobs, leading to a more pronounced polarization of the employment structure (Goos \& Manning, 2007).

Long-term changes in the employment structure are heavily influenced by compositional effects and do not necessarily imply analogue patterns of individual-level transitions (Cortes, 2016; Kurer \& Gallego, 2019). Table 3 shows transition rates between task groups and confirms this notion. To simplify the presentation of results, I report occupational transitions between the first and last observation of each respondent in each of the panel surveys. ${ }^{8}$

Despite the strong decline in the aggregate, on the individual level, survival in routine work is not uncommon. The column percentages show that around $65 \%-75 \%$ of respondents that entered the panels as routine workers are still in routine work the last time they answer the survey. At first sight, this might look like a relatively large share but the degree of stability in the two other task groups put this number into perspective. In nonroutine jobs, transitions are rarer and stability is especially high in nonroutine cognitive occupations $(>85 \%)$. Hence, while survival in routine work is fairly common, the structural long-term pressure on these occupations results, as expected, in a higher number of out-transitions. In terms of the transitions' direction, upgrading into more sophisticated nonroutine cognitive jobs is apparently not an impossible exit route for routine workers-despite different requirements with regard to skills and, often, formal education. In all three countries, upgrading is slightly more common than downgrading. 


\section{Employment Trajectories and Vote Intention}

The next step is to link different occupational trajectories to individual political responses. Tables 4 to 6 report the baseline probability to support the party indicated in the top row among survivors in routine work who, in line with the theoretical reasoning above, represent the reference category. The following three rows then display the effects of the three different treatments, that is, upgrading, downgrading, or dropping out. I run separate linear weighted regressions for each party. In the Supplemental Material, I report very similar results of a multinomial logistic specification.

The baseline probabilities in the first row confirm our expectation that right-wing populist parties (RPP) are successful in mobilizing survivors in routine work. Although large parts of routine work belong to the traditional core constituency of the Left, RPPs have been proved a strong competitor for these votes. In the presence of an influential right-wing populist party, the traditional preserve of the Left turns into a "contested stronghold" (Oesch \& Rennwald, 2018). Evidently, traditional mainstream conservative parties are less successful in mobilizing among this constituency. With respect to alternative political options, market-liberal parties are a much less likely choice for routine workers and self-reported abstention is comparatively rare in Switzerland and Germany, while British data seem to produce more realistic estimates of nonvoting. ${ }^{9}$

How do transitions out of routine work affect vote intention? The coefficients in the following tables report the change in the probability to vote for the specific party of the respective model if an individual switches from the reference category, routine work, into one of the three above-defined alternatives. The most important finding is that a transition from routine work into unemployment results in a strong and consistent decline in support for the most conservative party in all three countries. The results for Switzerland and the United Kingdom provide consistent evidence that it is indeed primarily "surviving" in routine work that fuels support for RPPs, while materialized economic hardship, that is, a transition into unemployment immediately and substantially reduces this support. Former routine workers' probability to vote for the Swiss Peoples Party or the UKIP, respectively, declines substantially once they lose their job and are unable to find another one.

In the absence of an RPP, the results show similar patterns of voting behavior with respect to conservative parties. Support among now-unemployed routine workers decreases substantially in Germany as well as in the United Kingdom, where the Conservative Party has not faced competition from the Right until 2013. Insofar, conservative parties seem to act as a second-best solution to satisfy routine workers' desire for the status-quo ante. 


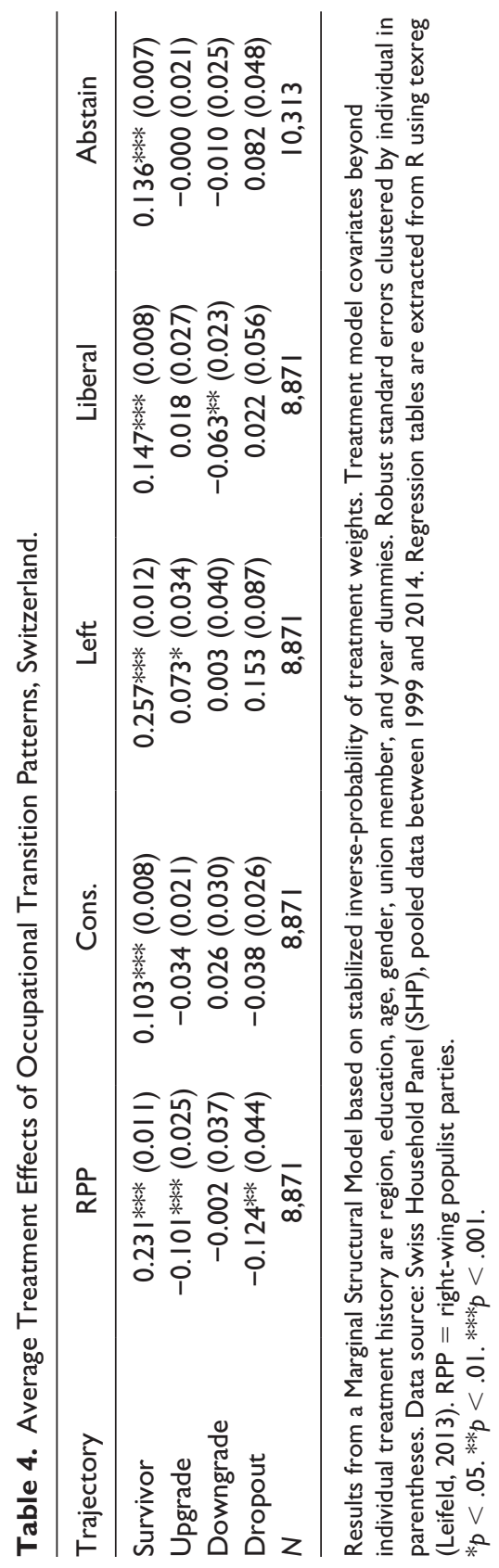




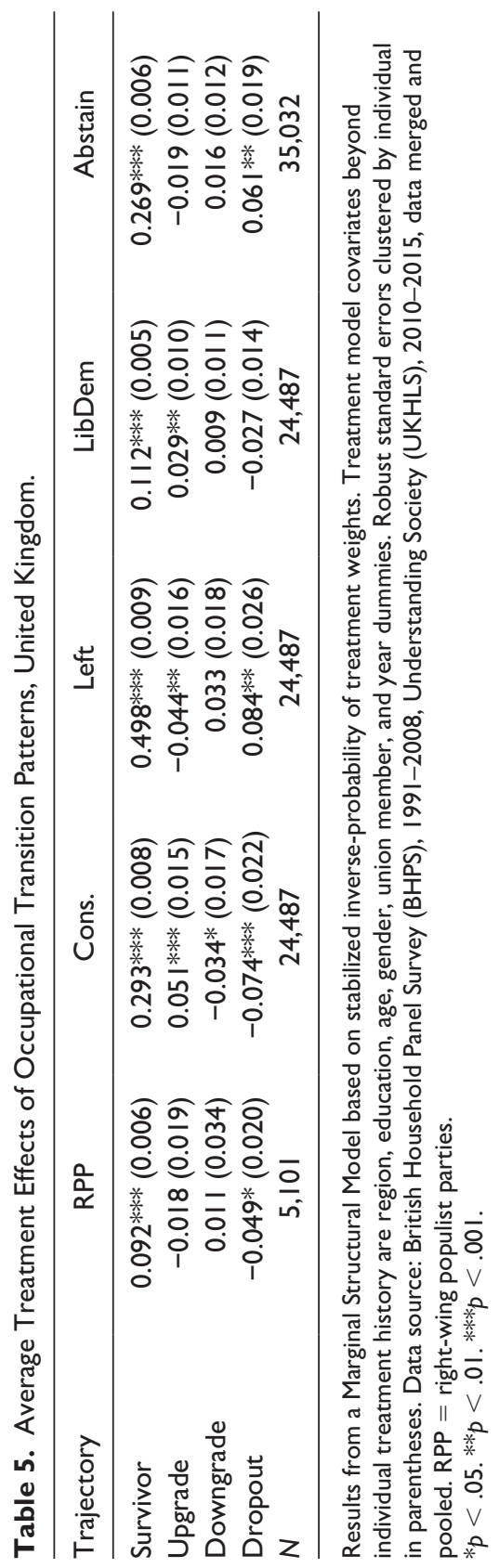




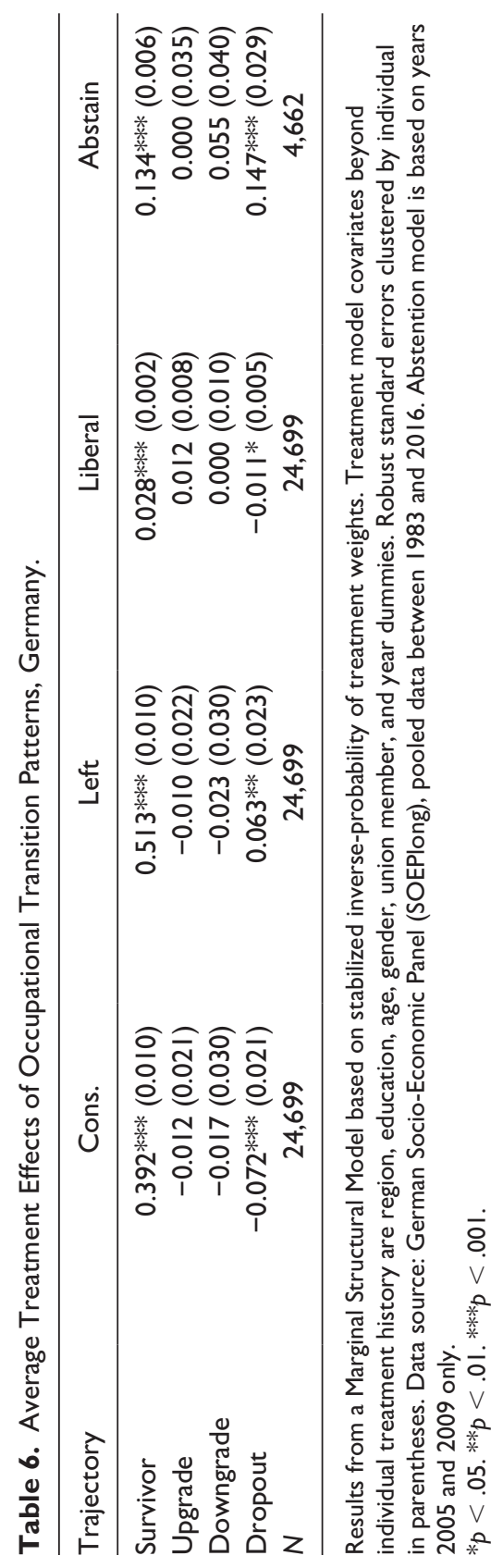


The voting behavior of dropouts supports the main claim of this article: It is fear of social decline rather than the actual experience of economic hardship, which drives support for parties who seek to "turn back the clock" (Gest et al., 2017) and promote socially conservative values.

While the first model offered evidence that transitions out of routine work indeed reduce support for right-wing populist or conservative parties, the following three models give an indication of which parties are supported instead. The picture with respect to dropouts is very consistent and goes in two different directions. ${ }^{10}$ Dropping out of the labor market either produces an economic response that leads to increasing support for left parties who stand for a strong social safety net. A further subanalysis for Germany shows that this effect is particularly pronounced with respect to far-left parties ("Die Linke") with an especially fierce position on defending a generous welfare state. The second significant political reaction of dropouts is growing political disenchantment. As a consequence of becoming unemployed, abstention rates among former routine workers increase between 6.1 (United Kingdom), 8.2 (Switzerland), and almost 15 percentage points (Germany).

As expected, the results for upgraders and downgraders are less consistent and offer mixed evidence. Upgraders in Switzerland increasingly support the Social Democrats, which might be explained by the strongly changing class basis of the Swiss Social Democratic Party, whose constituency is increasingly dominated by high-skilled and relatively well-off citizens (Rennwald, 2014). In contrast, German and British upgraders instead increasingly support pro-market liberal parties, as hypothesized. In the United Kingdom, they vote for both the conservatives as well as the Liberal Democrats, in Germany primarily for the FDP.

The results for downgraders are generally weak. Apart from lower support for pro-market liberal parties in Switzerland and the conservatives in the United Kingdom, there is no systematic pattern that differentiates the voting behavior of routine workers who remain in routine work and those who are forced to downgrade into lower skilled nonroutine jobs. Despite the experience of an occupational downgrade, these individuals still largely share the political preferences of routine workers. This noneffect has substantive meaning: Right-wing populist parties enjoy ongoing or even increasing success in spite of the steadily shrinking electoral weight of routine workers. Downgraders seem to partly compensate for shrinking share of RPP voters in routine jobs: Displaced into lower skilled service jobs, former routine workers still support the same parties.

Taken together, socially conservative parties find support among "survivors" in routine work, who share a bright past and rather bleak future prospects - but hold on to their dwindling position in the labor market. In stark 
contrast, at-risk routine workers who effectively lose their jobs react by increasingly voting for pro-welfare parties or by abstaining from the ballot box altogether. Absolute economic hardship does not appear as a driver of support for socially conservative or right-wing populist parties.

\section{Robustness}

The presented results adjust for confounding and posttreatment bias under four assumptions of consistency, exchangeability, positivity, and no misspecification. There is no empirical test to verify these assumptions, but credibility in the presented estimates can be increased by the means of sensitivity tests (Cole \& Hernán, 2008). The Supplemental Information to this article provides extensive robustness checks to examine the stability of the presented results. Particular emphasis is given to the specification of the treatment model. Two aspects are examined more closely: the selected predictors of treatment assignment and the exact estimation of the inverse-probability weight, a particularly sensitive aspect of marginal structural models (Blackwell \& Glynn, 2018; Imai \& Ratkovic, 2015). A detailed sensitivity analysis demonstrates the robustness of the estimates in the baseline model. The effect of becoming unemployed on voting for a right-wing populist party hardly at all changes across the seven different specifications examined in this sensitivity analysis. The size of the effect remains within a narrow range of about two percentage points and is strongly significant in each model. This increases confidence that the presented changes in the probability to support a specific party are caused by individual occupational transitions out of routine work.

In addition, I show multinomial logistic specifications instead of separate linear models, demonstrate that the findings are robust to an end-of-study outcome model (perhaps the most frequent application of MSMs), and that the results in the United Kingdom hold if I restrict the sample to BHPS respondents (i.e., excluding respondents that entered the study only in 2010 with the start of the broader UKHLS sampling).

Finally, I reproduce the results (to the extent possible) with a more traditional fixed-effects approach. The above discussed complications of dynamic longitudinal analysis with repeated treatments demand a very careful application of fixed-effects regressions and time-varying covariates. Yet, an additional empirical approach can still help clarify what the results from the preferred baseline models mean relative to alternative specifications. I detail the approach and report the results in the Supplemental Material. In line with the above analysis and comparable recent evaluations based on Dutch data (Gidron \& Mijs, 2019; Wiertz \& Rodon, 2019), former routine workers who lose their jobs do not show any sign of moving to the right. To the contrary, 
support for socially conservative parties decreases substantially in Switzerland and to a lesser extent also in the United Kingdom and Germany. Instead, nowunemployed former routine workers have higher probabilities to vote left (in the United Kingdom) or abstain (in Switzerland and, especially, Germany). The results are weaker and produce smaller effect magnitudes compared to the MSMs. I interpret the findings of this additional robustness check as confirmatory of the general thrust of the analysis but suggest that the reported size of the main effects might be seen as an upper rather than a lower bound.

\section{From Automation to Status Decline to Voting}

The above analysis suggests that support for right-wing populist parties is not primarily driven by the experience of economic hardship. To the contrary, losing a routine job and becoming unemployed consistently reduces support for conservative and right-wing populist parties. I have argued that survivors in routine work experience relative economic decline, which increases the salience of social conservatism and outgroup hostility vis-a-vis welfare state politics. However, the analysis so far was not able to directly validate the proposed mechanism. The employed panel data are limited with respect to subjective perception items and none provides questions about perceived social status.

I address this shortcoming by providing illustrative evidence from two additional data sources. The aim is twofold. First, I seek to underscore the basic narrative of a relative decline in subjective social status among routine workers compared to nonroutine groups over time. To this end, I employ data from the International Social Survey Program (ISSP), which conducts annual surveys since 1984 and some waves include otherwise rarely asked questions on subjective social status. Second, I wish to provide support for the suggested underlying mechanism, that is, the claim that susceptibility to automation creates status anxiety, which in turn fuels support for right-wing populist parties. To the best of my knowledge, no existing individual-level data set covers all of these issues. I therefore rely on an original survey that was fielded in eight Western European countries in late 2018. ${ }^{11}$

Figure 4 shows the results of the over-time analysis of relative social status based on ISSP data for the same countries as in the previous analysis. The specific survey item asks respondents to indicate their perceived place on the social ladder, where some groups tend to be toward the bottom $(0)$ and some toward the top (10) of society. As expected, routine and NRM workers have on average lower levels of subjective status compared to high-skilled nonroutine cognitive workers. However, the interesting aspect of Figure 4 is how these perceptions change relative to each other over time. Whereas routine 


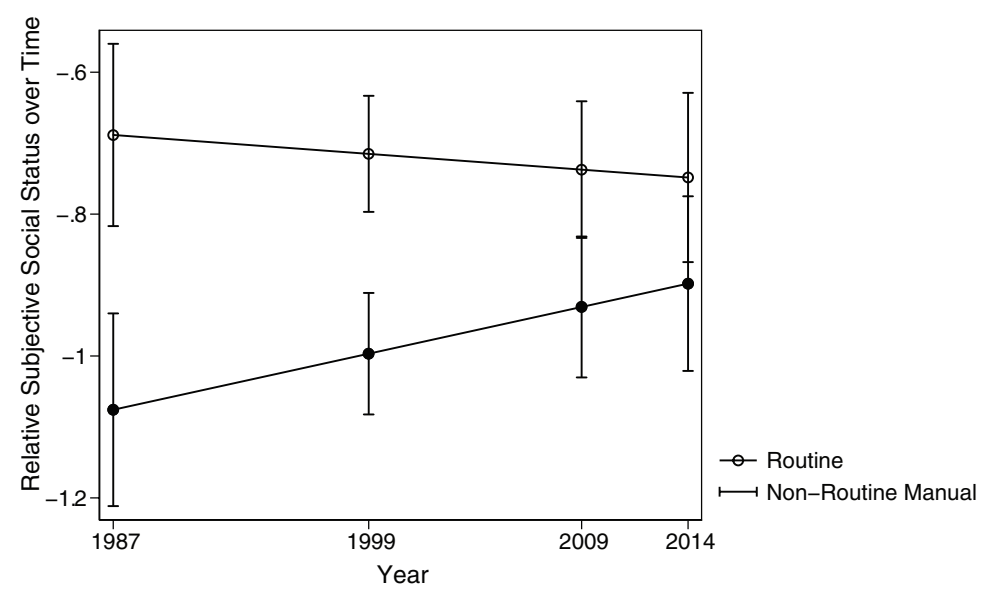

Reference Group: Non-Routine Cognitive. Covariates: Age, Gender, Education and Country FE.

Figure 4. Marginal effect of task group on subjective social status over time.

workers felt significantly closer toward the top of the societal scale than NRM workers in 1987, this difference almost disappears in the following 30 years. Although routine workers assess their position vis-a-vis nonroutine cognitive workers in almost the same way in 2014 and 1987, in comparison to lower status groups, their societal position clearly deteriorates.

Are such differences in subjective social status related to technologyinduced occupational change and do they affect the individual propensity to support right-wing populist parties? Figure 5 plots results from a series of analyses based on our original survey data. (The corresponding regression tables are provided in the Supplemental Information.) Panel A confirms a basic assumption of this article, namely that objectively higher rates of automation risk among routine workers are in fact reflected in individual perceptions. We asked respondents about the probability that their job will be automated within the next 10 years. Routine workers indeed estimate this risk to be significantly higher than workers employed in either of the two nonroutine groups.

The second panel then looks at the relationship between risk of automation and changing positions in the social hierarchy. I tried to overcome the lack of longitudinal variation in a cross-sectional survey by explicitly asking respondents about change (compared to their parents' generation) rather than level of subjective social status. The results of the underlying ordered logit 


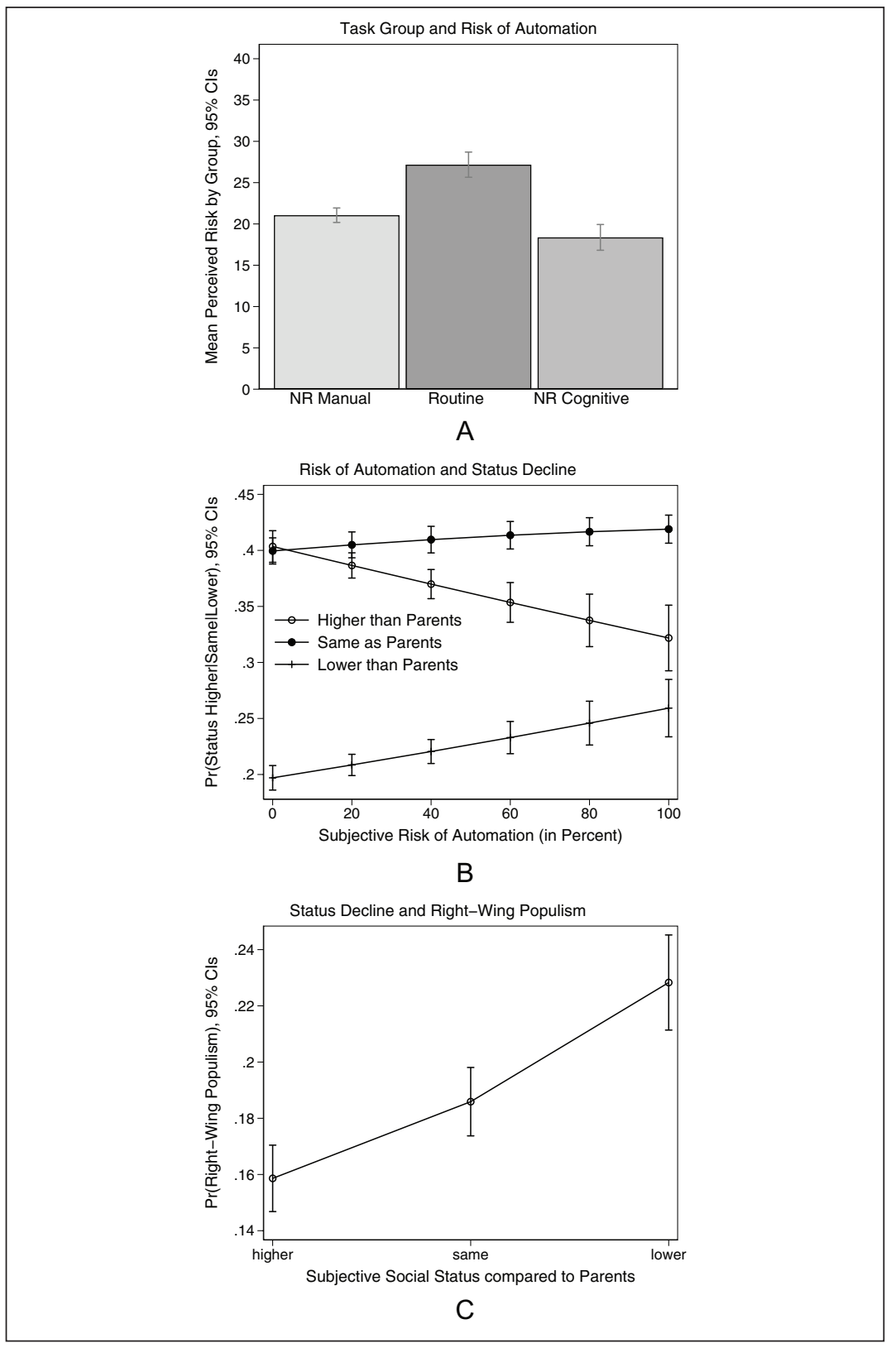

Figure 5. Tracing the mechanism: (A) risk of automation, $(B)$ status decline, and (C) right-wing populism.

$\mathrm{Cl}=$ confidence interval; $\mathrm{NR}=$ nonroutine . 
models, which include individual-level controls (gender, age, education, and employment status) and country-fixed effects, are displayed as predicted probabilities of higher/same/lower status conditional on perceived risk of automation. As expected, more pessimistic labor market prospects are associated with more negative perceptions of social status. The higher (lower) a respondent estimates her risk of replacement by new technologies, the higher his probability of perceived downward (upward) mobility.

Panel C, finally, brings the argument full circle by examining the relationship between status decline and party choice. I display predicted probabilities from a linear probability model including the same covariates as before. In line with findings by Gidron and Hall (2017), there is an unambiguously positive association between individual perceptions of status decline and support for right-wing populist parties. ${ }^{12}$ An additional subsample analysis in the Supplemental Information to this article demonstrates that the suggested mechanism indeed applies primarily to (male) routine workers, that is, the group at the center of interest.

Although this additional evidence from cross-national data is not directly linked to the above panel analysis, it still offers additional insights into how occupational change, subjective social status, and vote choice relate to each other. I conclude that (a) routine workers' social status has slightly decreased in absolute terms but especially in relative terms compared to lower status groups, that (b) these changes in perceptions of social hierarchies are related to subjective labor market prospects and susceptibility to automation, and that (c) perceived status decline is a relevant determinant of right-wing populist voting. Taken together, the presented observational evidence supports the notion that survivors in routine work are conscious about their deteriorating position in the social hierarchy and that this experience can trigger political demands that are apparently satisfied by the promises of right-wing populist parties.

I underscore this latter point by a final auxiliary analysis that addresses the question whether and to what extent radical left parties are able to mobilize voters suffering from status anxiety. I argued above that the combination of social conservatism that promotes the values of an idealized past and the hostile attitude toward lower status groups offer the most attractive package to routine workers who are doing alright in economic terms but experience relative decline in the social hierarchy. This expectation is indeed borne out by the data. While, in the overall sample, there is also a positive correlation between status decline and support for radical left parties, routine workers feel much more drawn toward the right. The overall level of support as well as the strength of the correlation is much higher for radical right as opposed to radical left parties. Not unexpectedly, there seems to be a common theme 
among radical nonmainstream parties that attracts voters who are dissatisfied with the status quo. However, when it comes to an anxious lower middle class in search for status enhancement but not in need of economic support, right-wing populist promises are uniquely alluring.

\section{Discussion and Conclusion}

Many postindustrial societies have recently been disrupted by unprecedented levels of anti-establishment rhetoric and the rise of new parties that challenge the democratic status quo. This article studies in how far technological change and the associated transformation of the employment structure contribute to this development. I examine the political behavior of routine workers, a large and influential part of the labor force that is particularly exposed to workplace automation. As a core contribution, I disentangle the political implications of fearing as opposed to experiencing economic decline.

The gradual but momentous decrease in demand for routine work in postindustrial labor markets provides an ideal setting for this endeavor. I differentiate between, on one hand, "survivors" in routine work who manage to cling to their jobs and maintain their mid-range incomes but perceive their relative position in the social hierarchy to be declining. On the other hand, I study political responses among "dropouts," that is former routine workers who have been made redundant by new technology and thus face the material consequences of jobloss. I find that surviving in an environment of structural decline drives support for right-wing populist parties, whereas the actual experience of economic hardship immediately and substantively reduces this support.

To be sure, this paper only provides a partial explanation of the widespread success of right-wing populist forces on both sides of the Atlantic. There are certainly other groups beyond routine workers who find the promises of right-wing populist parties appealing and they might do so based on different motives. And yet, routine workers' support of right-wing populist parties demonstrates that the presented argument has considerable traction and might well reach beyond the group considered here. It is not difficult to imagine various additional sources of perceived relative decline and status anxiety in a fast-paced risk society (Beck, 1986). Moreover, automation, computerization, and machine learning techniques have undoubtedly not yet reached their peak and will continue to transform the world of work in the years to come. Technological change will affect sections of the labor force that have so far been spared from the threat of automation and will thus constantly preserve or even enlarge the pool of voters who are receptive to political programs addressing status anxiety. Given the structural roots of the 
presented findings, there is much reason to expect right-wing populist parties to become a constant feature of the political arena in postindustrial democracy.

What makes this development so fascinating from a political science perspective is the difficulty of an adequate policy response. When it is not actual economic adversity that drives political resentment among relative losers of occupational change, "more welfare" in the traditional sense might not help alleviate grievances. Such an interpretation of my findings is also reflected in the sobering conclusion of a recent study on electoral consequences of social spending by Gingrich (2019). Not unexpectedly, welfare retrenchment is electorally harmful and tends to benefit right-wing populist mobilization. However, importantly, the reverse mechanism (more spending, less populism) is not borne out by Gingrich's data. This asymmetry highlights mainstream parties' limited leeway to compensate relative losers of economic modernization.

Rather than receiving financial support from governments, these voters want their perceived relative decline in the social hierarchy addressed. Rightwing populist parties have long recognized this. Their programmatic proposal, whether politically viable or not, should not be trivialized as mere populist seduction void of content but as a political offer to the sizable part of the population who faces rather bleak prospects and fears social regression. The limited capacity of governments to effectively attenuate political grievances among those adversely affected by relentless technological progress highlights the strategic disadvantage of responsible center-right or center-left parties in contemporary democracy. It renders postindustrial societies vulnerable to political forces responding to voters on the grounds of less tangible identity politics, which are difficult to counter with mundane, precise, and politically feasible policy reactions.

Further research will be needed to answer additional questions brought up by the above analysis. It might be a worthwhile avenue to look more closely into potentially heterogeneous effects of labor market transitions. This article is based on a parsimonious economic framework, which bundles different types of jobs and individuals within relatively broad task groups. Future research could examine differences between blue- and white-collar routine workers or differences between male and female routine workers. Furthermore, questions of intergenerational mobility might also contribute to political reactions as the occupational path of lifelong employment in routine work becomes increasingly unlikely. How individuals perceive an environment of structural decline clearly depends on many individual and contextual characteristics. Studying these characteristics will further improve our understanding of the political fallout of technological change. 


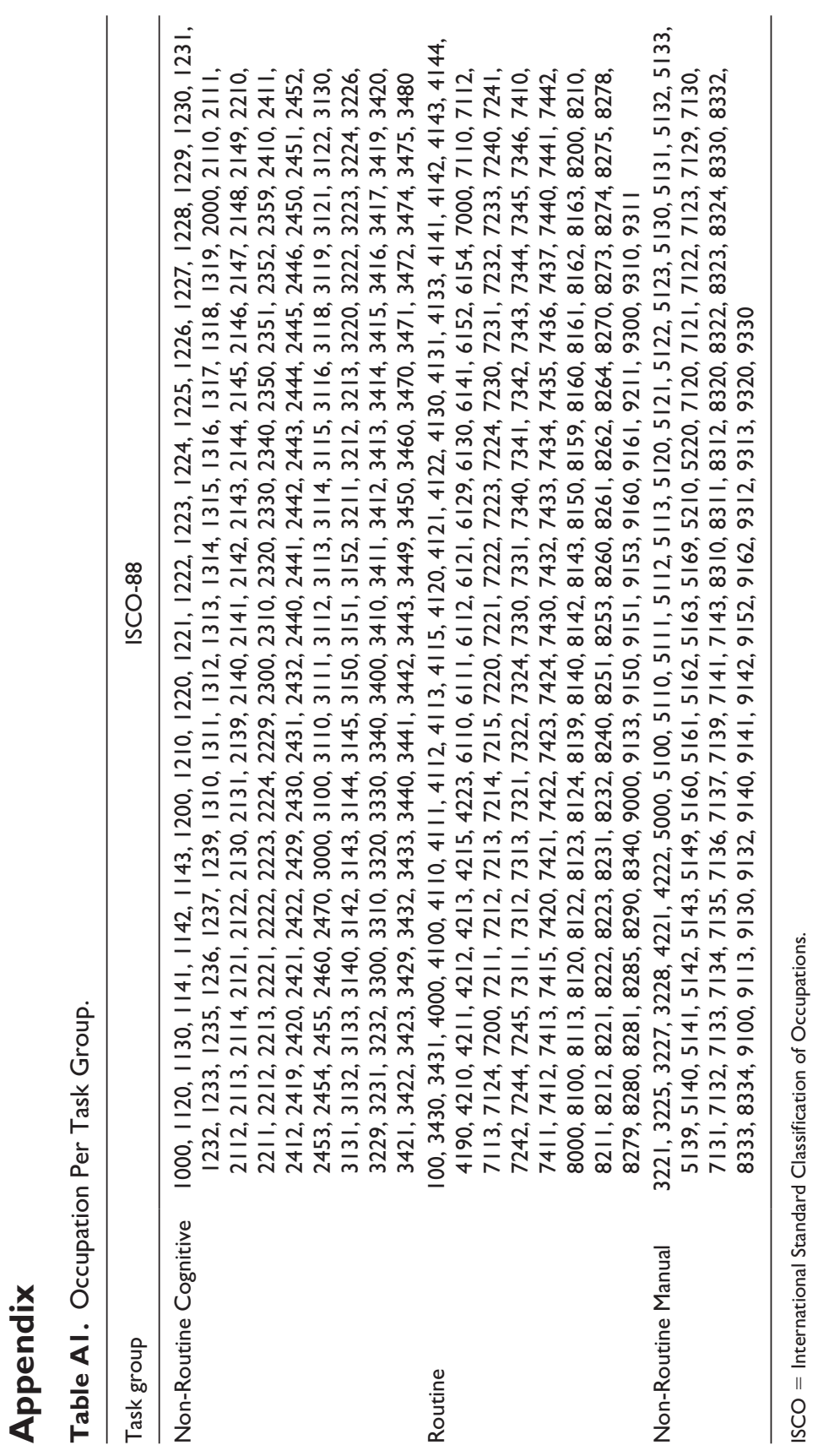




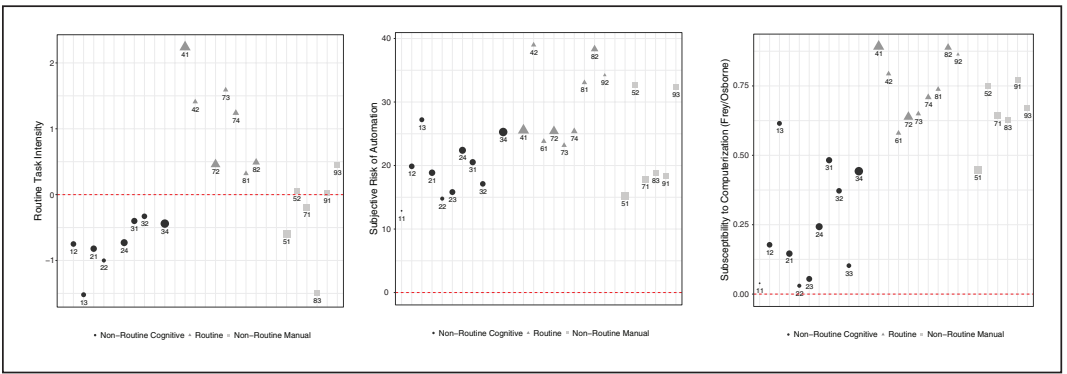

Figure AI. Occupations (ISCO-88) by task group, weighted by share: (A) RTI, (B) subjective, and (C) Frey/Osborne.

ISCO = International Standard Classification of Occupations; RTI = routine-task intensity.

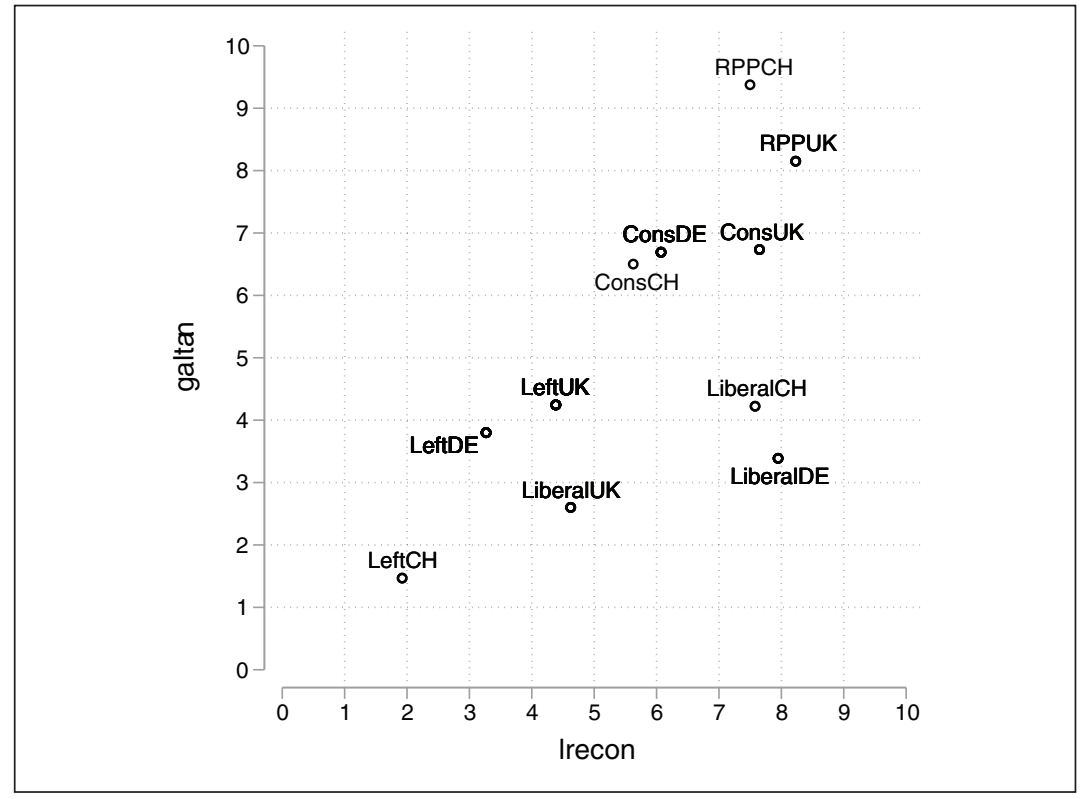

Figure A2. Ideological mapping of party families (Chapel Hill Expert Survey [CHES], weighted by vote share).

$\mathrm{RPP}=$ right-wing populist parties. 
Table A2. Dependent Variable: Operationalization.

Switzerland

\begin{tabular}{|c|c|c|}
\hline Variable & $p p / 9$ & Party choice in case of elections tomorrow \\
\hline \multirow[t]{5}{*}{ Operationalization } & RPP & Schweizerische Volkspartei (SVP) \\
\hline & Cons. & Christlich-Demokratische Volkspartei (CVP) \\
\hline & Left & $\begin{array}{l}\text { Sozialdemokratische Partei (SP); Gruene Partei (GPS); } \\
\text { Partei der Arbeit (PdA); Alternative/Solidaritee }\end{array}$ \\
\hline & Liberal & FDP. DieLiberalen; Gruenliberale Partei (GLP) \\
\hline & Abstention & Vote for no party \\
\hline \multicolumn{3}{|l|}{ Germany } \\
\hline Variable & plh00I2 & Which political party do you support? \\
\hline \multirow[t]{3}{*}{ Operationalization } & Cons & $\begin{array}{l}\text { Christlich-Demokratische Union (CDU); Christlich-Soziale } \\
\text { Union (CSU) }\end{array}$ \\
\hline & Left & $\begin{array}{l}\text { Sozialdemokratische Partei Deutschlands (SPD); Buendnis } \\
\text { Gruene.90; Die Linke }\end{array}$ \\
\hline & Liberal & Freie Demokraten (FDP) \\
\hline Variable & plh0003 & Voted in last Bundestagswahl (available 2005 and 2009) \\
\hline Operationalization & Abstention & did not vote \\
\hline
\end{tabular}

UK

\begin{tabular}{|c|c|c|}
\hline Variable & Vote3 & Which party would you vote for tomorrow \\
\hline \multirow[t]{4}{*}{ Operationalization } & RPP & United Kingdom Independence Party (from 20I3) \\
\hline & Cons & Conservative Party \\
\hline & Left & Labor Party; Scottish National Party; Greens \\
\hline & LibDem & Liberal Democrats \\
\hline Variable & Vote7 & $\begin{array}{l}\text { Did you vote in [month, year] UK general election? } \\
\text { (unbalanced) }\end{array}$ \\
\hline Operationalization & Abstention & $\begin{aligned}\text { did not vote (vote } 7==2) \text { OR would not vote for any party } \\
\text { tomorrow (vote } 3==95)\end{aligned}$ \\
\hline
\end{tabular}

RPP $=$ right-wing populist parties.

Table A3. In-Sample Transitions of (Former) Routine Workers.

\begin{tabular}{|c|c|c|c|}
\hline & $\mathrm{CH}$ & $\mathrm{DE}$ & UK \\
\hline Trajectory & $\%$ & $\%$ & $\%$ \\
\hline Upgraders & 4.5 & 5.1 & 10.2 \\
\hline Survivors & 90.8 & 87.0 & 77.5 \\
\hline Downgraders & 3.2 & 4.1 & 8.8 \\
\hline Dropouts & 1.4 & 3.8 & 3.4 \\
\hline
\end{tabular}

CH: Switzerland; DE: Germany; UK: United Kingdom. 


\section{Authors' Note}

Previous versions of this manuscript have been presented at ESPAnet 2016, SVPW 2017, MPSA 2017, CES 2017, Nuffield College Graduate Conference 2017, ECPR 2017, Populism Workshop 2019 at Harvard as well as in seminars at Universities of Zurich, Oxford, Sciences Po, and Stockholm.

\section{Acknowledgments}

I thank all the participants of the above meetings as well as Silja Häusermann, Christopher Wratil, Tarik Abou-Chadi, David Autor, Hans-Georg Betz, Matt Blackwell, Denis Cohen, Olle Folke, Aina Gallego, Noam Gidron, Jane Gingrich, Peter Hall, Torben Iversen, Cloé Jans, Hanspeter Kriesi, Brian Nolan, Nils Redeker, David Rueda, Dani Rodrik, Stefan Thewissen, Chloé Touzet, Stefanie Walter, David Willumsen and various anonymous reviewers for very helpful comments and discussions. All remaining errors are my own.

\section{Declaration of Conflicting Interests}

The author declared no potential conflicts of interest with respect to the research, authorship, and/or publication of this article.

\section{Funding}

The author disclosed receipt of the following financial support for the research, authorship, and/or publication of this article: This research was supported by the Swiss National Science Foundation (Grant Number 146104 and 171881).

\section{ORCID iD}

Thomas Kurer (iD https://orcid.org/0000-0003-2339-6282

\section{Supplemental Material}

Supplemental material for this article is available online at the CPS website http:// journals.sagepub.com/doi/suppl/10.1177/0010414020912283

\section{Notes}

1. In the near future, automation will threaten many of those low-skilled jobs in the service sector, too. The focus of this study is on the past and contemporary impact of technological change. More forward-looking perspectives lend themselves for debating expected repercussions in coming years but not for an empirical analysis of observed political behavior.

2. At first sight, so-called welfare chauvinist parties might seem an option to bridge competing demands. However, it is unlikely for voters with a primary demand in a strong welfare state to support such parties. The left is still a much more credible supporter of a generous social safety net. If, however, voters have a 
secondary preference for social security beyond their primary concerns about status maintenance, welfare chauvinist parties offer a very attractive policy package.

3. Moreover, the "last-place aversion" theory suggests that concerns about one's relative position in the social hierarchy might depress demand for redistribution even among citizens who, in theory, should be supportive (Kuziemko et al., 2014). This is due to concerns that welfare might disproportionately benefit lower status groups, which counteracts the goal of relative status enhancement.

4. Figure A2 provides a positional mapping of the parties under study.

5. This situation has changed with the rise of the Alternative fuer Deutschland (AfD). Founded in April 2013 as an anti-Euro party, it has continuously morphed into a typical right-wing populist party. Unfortunately, the low number of respondents who indicate AfD support in recent waves makes it impossible to test H1a in Germany because key assumptions of the estimation model are violated (details in the following).

6. Whenever available, $p$ is a one-year lag. $p$ gets larger - but is restricted to a maximum of 5 years - if a respondent's information is missing in one or more years. $p$ is always the most proximate past observation, so it is not possible to go through different treatments per lag.

7. As recommended by the literature, weights are stabilized by treatment history and time-invariant covariates (van der Wal \& Geskus, 2011). The sensitivity analysis in the Supplemental Information to this article demonstrates the superiority of this approach to nonstabilized weights.

8. The actual distribution of transitions in the below analysis is even more strongly dominated by survivors in routine work because I focus on respondents who remain or transition out of routine work. Once they permanently leave routine work, they also drop out of the sample (see Table A3 in the appendix). An individual who has been working in routine work for 5 years and then upgrades to nonroutine cognitive work will contribute four observations to the survivor category and one observation to the upgrader category.

9. The operationalization of abstention with Swiss data is not ideal as the household survey does not report turnout directly (see Table A2).

10. The effects for Switzerland with by far the lowest number of transitions into unemployment in the final model are less precisely estimated with $p$ values of .078 and .085 , respectively.

11. Denmark, Germany, Ireland, Italy, Netherlands, Spain, Sweden, and United Kingdom. More details on sampling and dataset are provided in the Supplemental Information.

12. The following parties are coded as right-wing populist: DK: Danish People's Party; DE: Alternative for Germany; IT: Lega Nord; NL: Party for Freedom; SE: Sweden Democrats; UK: United Kingdom Independence Party. Ireland and Spain are thus not included in this analysis. The correlation is robust to alternative model specifications (logit), different coding of the dependent variable, as well as the exclusion of potential outliers (see Supplemental Information). 


\section{References}

Acemoglu, D., \& Autor, D. (2011). Skills, tasks and technologies: Implications for employment and earnings. In O. Ashenfelter \& D. Card (Eds.), Handbook of labor economics (pp. 1043-1171). Elsevier.

Andersen, J. G., \& Bjørklund, T. (1990). Structural changes and new cleavages: The progress parties in Denmark and Norway. Acta Sociologica, 33(3), 195-217.

Anelli, M., Colantone, I., \& Stanig, P. (2019). We were the robots: Automation and voting behavior in Western Europe. https://papers.ssrn.com/sol3/papers. cfm?abstract id $=3427624$

Antonucci, L., Horvath, L., Kutiyski, Y., \& Krouwel, A. (2017). The malaise of the squeezed middle: Challenging the narrative of the "left behind" Brexiter. Competition \& Change, 21(3), 211-229.

Ares, M. (2020). Changing classes, changing preferences: How social class mobility affects economic preferences. West European Politics, 43(6), 1211-1237.

Autor, D. H., \& Dorn, D. (2009). This job is "getting old": Measuring changes in job opportunities using occupational age structure. American Economic Review, 99(2), 45-51.

Autor, D. H., Dorn, D., \& Hanson, G. H. (2013). The geography of trade and technology shocks in the United States. The American Economic Review, 103(3), $220-225$.

Autor, D. H., Levy, F., \& Murnane, R. J. (2003). The skill content of recent technological change: An empirical exploration. The Quarterly Journal of Economics, $118(4), 1279-1333$.

Bacak, V., \& Kennedy, E. H. (2015). Marginal structural models: An application to incarceration and marriage during young adulthood. Journal of Marriage and Family, 77(1), 112-125.

Beck, U. (1986). Risikogesellschaft: auf dem Weg in eine andere Moderne [Risk Society: Towards a New Modernity]. Suhrkamp.

Blackwell, M. (2013). A framework for dynamic causal inference in political science. American Journal of Political Science, 57(2), 504-520.

Blackwell, M., \& Glynn, A. N. (2018). How to make causal inferences with timeseries cross-sectional data under selection on observables. American Political Science Review, 112(4), 1067-1082.

Bornschier, S., \& Kriesi, H. (2013). The populist right, the working class, and the changing face of class politics. In J. Rydgren (Ed.), Class politics and the radical right (pp. 11-29). Routledge.

Burgoon, B., van Noort, S., Rooduijn, M., \& Underhill, G. (2019). Positional deprivation and support for radical right and radical left parties. Economic Policy, 34(97), 49-93.

Cole, S. R., \& Hernán, M. A. (2008). Constructing inverse probability weights for marginal structural models. American Journal of Epidemiology, 168(6), 656-664.

Cortes, G. M. (2016). Where have the middle-wage workers gone? A study of polarization using panel data. Journal of Labor Economics, 34(1), 63-105. 
Ekberg, M. (2007). The parameters of the risk society: A review and exploration. Current Sociology, 55(3), 343-366.

Feldman, S., \& Stenner, K. (1997). Perceived threat and authoritarianism. Political Psychology, 18(4), 741-770.

Frey, C. B., Berger, T., \& Chen, C. (2018). Political machinery: Did robots swing the 2016 US presidential election? Oxford Review of Economic Policy, 34(3), 418-442.

Frey, C. B., \& Osborne, M. A. (2017). The future of employment: How susceptible are jobs to computerisation? Technological Forecasting and Social Change, 114, 254-280.

Gest, J., Reny, T., \& Mayer, J. (2017). Roots of the radical right: Nostalgic deprivation in the United States and Britain. Comparative Political Studies, 51(13), 1694-1719.

Gidron, N., \& Hall, P. A. (2017). The politics of social status: Economic and cultural roots of the populist right. The British Journal of Sociology, 68, S57-S84.

Gidron, N., \& Mijs, J. J. B. (2019). Do changes in material circumstances drive support for populist radical parties? Panel data evidence from the Netherlands during the great recession, 2007-2015. European Sociological Review, 35(5), 637-650.

Gingrich, J. (2019). Did state responses to automation matter for voters? Research \& Politics, 6(1), 1-9.

Goos, M., \& Manning, A. (2007). Lousy and lovely jobs: The rising polarization of work in Britain. Review of Economics and Statistics, 89(1), 118-133.

Goos, M., Manning, A., \& Salomons, A. (2014). Explaining job polarization: Routinebiased technological change and offshoring. The American Economic Review, 104(8), 2509-2526.

Im, Z. J., Mayer, N., Palier, B., \& Rovny, J. (2019). The "losers of automation": A reservoir of votes for the radical right? Research \& Politics, 6(1), 1-7.

Imai, K., \& Ratkovic, M. (2015). Robust estimation of inverse probability weights for marginal structural models. Journal of the American Statistical Association, 110(511), 1013-1023.

Inglehart, R. F., \& Norris, P. (2016). Trump, Brexit, and the rise of populism: Economic have-nots and cultural backlash (HKS Working Paper No. RWP16026). https://papers.ssrn.com/sol3/papers.cfm?abstract_id=2818659

Iversen, T., \& Soskice, D. (2001). An asset theory of social policy preferences. American Political Science Review, 95(4), 875-894.

Jahoda, M. (1982). Employment and unemployment: A social-psychological analysis. Cambridge University Press.

Jost, J. T., Glaser, J., Kruglanski, A. W., \& Sulloway, F. J. (2003). Political conservatism as motivated social cognition. Psychological Bulletin, 129(3), 339-375.

Küpper, B., Wolf, C., \& Zick, A. (2010). Social status and anti-immigrant attitudes in Europe: An examination from the perspective of social dominance theory. International Journal of Conflict and Violence, 4(2), 205-219.

Kurer, T., \& Gallego, A. (2019). Distributional consequences of technological change: Worker-level evidence. Research \& Politics, 6(1), 1-9. 
Kurer, T., \& Palier, B. (2019). Shrinking and shouting: The political revolt of the declining middle in times of employment polarization. Research \& Politics, 6(1), $1-6$.

Kuziemko, I., Buell, R. W., Reich, T., \& Norton, M. I. (2014). “Last-place aversion”: Evidence and redistributive implications. The Quarterly Journal of Economics, 129(1), 105-149.

Lahtinen, H., Wass, H., \& Hiilamo, H. (2017). Gradient constraint in voting: The effect of intra-generational social class and income mobility on turnout. Electoral Studies, 45, 14-23.

Leifeld, P. (2013). texreg: Conversion of statistical model output in R to LATEX and HTML tables. Journal of Statistical Software, 55(8), 1-24.

Murphy, E. C. (2014). Workers' movement out of declining occupations in Great Britain, Germany and Switzerland. European Sociological Review, 30(6), $685-701$.

Mutz, D. C. (2018). Status threat, not economic hardship, explains the 2016 presidential vote. Proceedings of the National Academy of Sciences, 115(19), E4330-E4339.

Nachtwey, O. (2016). Die Abstiegsgesellschaft: Über das Aufbegehren in der regressiven Moderne [Germany's Hidden Crisis Social Decline in the Heart of Europe]. Suhrkamp Verlag.

Oesch, D. (2008). Explaining workers' support for right-wing populist parties in Western Europe: Evidence from Austria, Belgium, France, Norway, and Switzerland. International Political Science Review, 29(3), 349-373.

Oesch, D. (2013). Occupational change in Europe: how technology and education transform the job structure. Oxford University Press.

Oesch, D., \& Rennwald, L. (2018). Electoral competition in Europe's new tripolar political space: Class voting for the left, centre-right and radical right. European Journal of Political Research, 57(4), 783-807.

Organisation for Economic Co-operation and Development. (2017). OECD employment outlook 2017. https://doi.org/10.1787/empl_outlook-2017-en

Parolin, Z. (2020). Organized labor and the employment trajectories of workers in routine jobs: Evidence from U.S. Panel Data. https://www.brookings.edu/ research/organized-labor-and-the-employment-trajectories-of-workers-in-routine-jobs-evidence-from-u-s-panel-data/

Peri, G., \& Sparber, C. (2009). Task specialization, immigration, and wages. American Economic Journal: Applied Economics, 1(3), 135-169.

Rehm, P. (2009). Risks and redistribution: An individual-level analysis. Comparative Political Studies, 42(7), 855-881.

Rennwald, L. (2014). Class (non) voting in Switzerland 1971-2011: Ruptures and continuities in a changing political landscape. Swiss Political Science Review, 20(4), 550-572.

Ridgeway, C. L. (2014). Why status matters for inequality. American Sociological Review, 79(1), 1-16. 
Riek, B. M., Mania, E. W., \& Gaertner, S. L. (2006). Intergroup threat and outgroup attitudes: A meta-analytic review. Personality and Social Psychology Review, 10(4), 336-353.

Robins, J. M. (1999). Association, causation, and marginal structural models. Synthese, 121(1), 151-179.

Robins, J. M., Hernan, M. A., \& Brumback, B. (2000). Marginal structural models and causal inference in epidemiology. Epidemiology, 11(5), 550-560.

Rodrik, D. (2018). Populism and the economics of globalization. Journal of International Business Policy, 1(1-2), 12-33.

Rosenstone, S. J. (1982). Economic adversity and voter turnout. American Journal of Political Science, 26(1), 25-46.

Rovny, A. E., \& Rovny, J. (2017). Outsiders at the ballot box: Operationalizations and political consequences of the insider-outsider dualism. Socio-Economic Review, 15(1), 161-185.

Spitz-Oener, A. (2006). Technical change, job tasks, and rising educational demands: Looking outside the wage structure. Journal of Labor Economics, 24(2), 235270.

Steenvoorden, E., \& Harteveld, E. (2018). The appeal of nostalgia: The influence of societal pessimism on support for populist radical right parties. West European Politics, 41(1), 28-52.

Thewissen, S., \& Rueda, D. (2019). Automation and the welfare state: Technological change as a determinant of redistribution preferences. Comparative Political Studies, 52(2), 171-208.

van der Wal, W. M., \& Geskus, R. B. (2011). ipw: An R package for inverse probability weighting. Journal of Statistical Software, 43(13), 1-23.

Wiertz, D., \& Rodon, T. (2019). Frozen or malleable? Political ideology in the face of job loss and unemployment. Socio-Economic Review. Advance online publication. https://doi.org/10.1093/ser/mwz024

Wilson, G. D. (1973). Psychology of conservatism. Academic Press.

\section{Author Biography}

Thomas Kurer is a senior researcher at the Department of Political Science, University of Zurich. He is interested in the political consequences of technological innovation and occupational change in post-industrial societies. 